\title{
Study on New Challenges Posed by New Changes in Minority Sports Cultural Needs to Existing Sports Cultural Policy Response Mechanism
}

\author{
Yingqing $\mathrm{Hu}^{1}$, Shaoju $\mathrm{Tan}^{1}$, Xinping Jiang ${ }^{2 \star}$ \\ ${ }^{1}$ Guangxi College of Sports and Physical Education, Nanning, 530012, China \\ ${ }^{2}$ Guangxi University For Nationalities, Nanning, 530006, China \\ ${ }^{*}$ Corresponding author
}

Keywords: minority, sports culture, changes, response mechanism, challenges

\begin{abstract}
At present, with constant development of the Chinese society and continuous improvement of people's material and cultural living conditions, Chinese minority cultural needs also show an increasing trend. However, at present stage, China's existing response mechanism of cultural needs is far behind growing spiritual and cultural needs. Based on this, this paper discusses about new challenges posed by new changes in minority sports cultural needs to existing sports cultural policy response mechanism.
\end{abstract}

\section{Introduction}

China is a multi-ethnic country with flourishing and strengthening ethnic cultures, which condense commonly into the wind of culture with unique ethnic characteristics. In particular, sports culture in minorities is an important component and is favored by the masses. Ethnic sports culture not only shoulders important task of maintaining social stability and giving the masses spiritual inspiration, but also is an important force to promote economic development of minority areas and push leapfrog social development. At present, lots of minority cultures attract visit and experience of the vast majority of tourists with distinctive features.

\section{New changes in minority cultural needs}

\section{Cultural value and power are given attention}

Continuous social development and especially people's more liberated thoughts since the reform and opening up promote constant attention of Chinese minorities to cultural value and power, and people have increasingly urgent needs in this respect. This is mainly reflected in the following two aspects: firstly, people gradually realize the value of their traditional ethnic cultures and attach importance to protection of unique ethnic cultures. Since the founding of New China, although minorities get precious room for peaceful development, traditional cultures of some minorities are classified as four olds and are seriously suppressed because of ultra-left thoughts and especially the impact of Cultural Revolution. Particularly, some very precious cultural relics, buildings and customs etc with elite cultures come down through thousands of years of minorities are damaged ruthlessly. Until the reform and opening up, traditional cultures of minorities are concerned again and protected. In recent years, with national support policies to promote leapfrog development of less developed minority areas and continuous development of national tourism industry, cultural value of minorities is gradually developed as tourism resources with brilliant results. Secondly, as special groups, minorities have strong interest in their ethnic cultures and demand of being protected and concerned. Thus, all levels of governments make a positive response to their cultural needs, such as increase efforts in supporting the development of public cultural services, promote cultural development of each minority actively and meet people's needs ${ }^{[1]}$.

\section{Minorities present to be increasingly open and inclusive to modern culture}

Cultural needs of minorities are not limited to their own traditional cultures. Actually, along with continuous social development, minorities' demand of modern culture also presents characteristics of openness and inclusiveness. Especially, minorities have stronger interest in advanced modern 
civilization and modern society of the outside world because of relatively low level of social development, and modern culture can arouse response and identity of minorities easier, showing stronger inclusiveness. For example, modern communication tools, television, vehicles, electricity and other new things have greater influence in minority areas. In recent years, China constantly issues policies to support the development of minority areas, and brings rare development opportunities for these relatively poor and backward areas. New generations of young people in minority areas have gradually get rid of original lifestyles of former generations, and tend more to modern society and civilization. When they return to their hometowns from modern metropolis, they bring modern civilization and cultures back to rural hometowns, and advanced cultures become important content of minorities' cultural needs.

\section{Cultural needs present to be obviously diverse}

In the past, people's material life was extremely scarce because of low social productivity and economic development level. In the age with insufficient food, filling the belly was the first priority, and cultural needs were very much weak compared with urgent material needs, let alone rich and colorful cultural life. However, with great improvement of material life since the reform and opening up, problem of food and clothing has long gone. In such a context, especially under continuous improvement of educational degree and level, cultural needs gradually show obvious diversity and develop toward a more individualized direction. Cultural activities in modern society like reading books, reading newspapers, surfing the internet, watching TV and fitness etc are increasingly popularized in life, and become indispensably important parts of life. This also happens in minority society, and requires cultural workers to concentrate efforts in the quality and quantity of cultural creation based on actual needs of minorities, in order to meet their diverse cultural needs effectively.

\section{The process of cultural industrialization and marketization in minority areas is accelerated increasingly}

Although cultural industry in China's minority areas has a late start and has an obvious gap with economically developed areas, it doesn't mean that minorities have not cultural needs. Especially in recent years, along with the deepening of China's market economy system reform, the decisive role of market in resource allocation is being revealed in minority areas. In cultural life, it is that the development course of cultural industrialization and marketization is being accelerated constantly. Through guidance and driving of the market, cultural industry becomes an important economic growth point in minority areas, and plays an important role in driving the development of local economy and cultural industry. Besides, a large number of ethnic cultural brands that are famous at home and abroad occur, such as "Impression of Sanjie Liu”, "Colorful Yunnan" and "Impression of Lijiang” etc, which greatly enrich cultural needs of local people and tourists. Of course, because of a large gap of the development of peripheral economic environment, cultural cause and cultural industry in minority areas still have a long way to go, which requires further emancipation of minds, innovation and reform, and striving to meet growing cultural needs of minority people ${ }^{[2]}$.

\section{New challenges in front of China's minority cultural need response mechanism}

\section{Contradictions between minority cultural needs and government response}

For a long time, there is a wrong and unilateral understanding of the development of minority areas, as it is believed that urgent needs of the development of minority areas lie in materials and economy instead of culture because their material life cannot be effectively satisfied. This view is actually very wrong, and minority areas do not have fewer cultural needs than developed areas, but they fail to release and express fully because of restrictions of economic development conditions. In particular, with continuous social development, they have stronger cultural needs if they see more about wonderful outside world. However, the government often inputs a great deal of manpower and material resources into local economic development, while shows an indifferent attitude towards people's cultural needs, and makes less response, so that cultural needs of minorities are not concerned and met. 


\section{Contradictions between cultural needs hierarchy of minorities and government response}

Contradictions between cultural needs hierarchy of minorities and government response are mainly reflected in: cultural popularization of the government is scientific and elegant, and often strongly political. Cultural needs of minorities are from needs of the public, and thus could not be totally advanced, but are more irrational, not elegant and closer to actual life. If not effectively coordinated and solved, such contradictions would often lead to vulgar cultural life of people easily, such as gambling and superstition etc.

3. Contradictions between timely and dynamic changes of minorities' cultural needs and lagged government response

In recent years, public infrastructure and cultural resources in minority areas have achieved great enrichment and development, but still have too many problems in front of people's growing needs. For example, "Village-to-Village Project" that is vigorously implemented in recent years encounters such embarrassment. In this project, the government aims at making less economically developed areas watch more programs, but there are almost no TV programs, films and TV series etc in ethnic languages for the minorities. Relative to timely and dynamic changes of minorities' cultural needs, government response is relatively lagged, resulting in certain contradictions.

4. Contradictions between target value of minorities' cultural needs and low efficiency of government response

Minorities have weak strength and would always depend on strong government support in terms of cultural development. Hopefully, the government could develop and provide more cultural products and services. However, it should be seen that the power of the government mainly comes from income of the masses. Most minority areas generally have not high economic development level, so that the government "lacks necessary materials to accomplish its intentions". Shortage of funds results in inadequate input into cultural needs, and such funds are tended to be input into social public affairs or expansion of reproduction and improvement of productivity. High goal of minorities' cultural needs has certain contradiction with low efficiency of government response.

\section{Several reflections on minority sports cultural development}

\section{Standardization of government response responsibility}

Conventionally, response of government departments to cultural needs can be seen as a flexible task that is not essential and can be big or small. Although government departments declare to increase efforts in development, such declaration just stays in words and can hardly be put into practice. It shall be known that our government shall not only serve the people, but also have responsibility to listen to people actively and respond to them timely. Government response to people's true feelings is both responsibility and obligation. Strengthen explicit and standardized evaluation and accountability of performance of relevant responsibilities in cultural needs, promote standardization of government response responsibility, and relevant management institutions shall not shirk responsibilities ${ }^{[3]}$.

\section{Vigorous promotion of leapfrog development of minority sports culture}

Currently, China faces unprecedented development and reform opportunities, in particular, economic growth slows down in traditional economically developed areas, and less developed areas become new economic growth points. This requires all levels of governments in minority areas to make enough and full use of national strategic guidance and policy support and strengthen regional cooperation; enhance opening to the outside world and excavation and publicity of their own traditional ethnic sports culture, and build a resounding featured brand of local ethnic sports culture; create innovative cooperation model, explore more vibrant investment promotion ideas actively, and promote development of tourism resources in local areas etc; form joint development forces through multiple ways, and promote leapfrog development of minority sports culture.

3. Establishment of more efficient cultural information coverage and transmission mechanism

In traditional cultural transmission and management model, people's cultural appeal is transmitted through layers, resulting in distortion and even great weakening of a large amount of information. As a result, cultural needs of the public cannot form enough strong power and voice 
loud enough to be accepted by the government, and thus effective policy response can hardly be obtained. This requires us to increase efforts in innovation of cultural information transmission modes, build a more efficient cultural information transmission mode, change it from single-channel into multi-channel, establish more efficient and comprehensive government-the public interaction network, form efficient cultural information coverage and transmission mechanism, and ensure rapid transmission of cultural information and government response.

\section{Vigorous promotion of industrialization and marketization of minority sports culture}

The importance of economic development to minority areas is self-evident. How to introduce cultural development during economic development in order to drive cultural development with economic power, cultural industrialization and marketization will be the only road. Driven by economic interests, more optimal allocation of manpower, material resources and technologies etc can be achieved. Industrialization and marketization of minority traditional sports shall be fully based on local reality, estimate their advantages rationally, and create featured brands actively. At present, some minorities in China have achieved success in this regard. For example, the Mongol Nationality in Inner Mongolia would hold Naadam Event annually, attracting a large number of tourists from home and abroad. In addition, Harbin has Ice Sculpture Festival and Skiing Festival etc. These events promote achievements in economy and sports culture while greatly improving local popularity and influence.

\section{Conclusions}

At present, with constant development of the Chinese society and continuous improvement of people's material and cultural living conditions, Chinese minority cultural needs also show an increasing trend. However, at present stage, China's existing response mechanism of cultural needs is far behind growing spiritual and cultural needs. Chinese minority cultural need response mechanism still faces many challenges, which require us to increase efforts in innovation and reform, form joint development forces through multiple ways, and promote continuous innovative development of minority sports culture.

\section{Acknowledgments}

This study is subsidized by Guangxi Philosophy and Social Sciences Planning Project "Study on Minority Sports Culture Policy Response Mechanism and National Identity”, Project Approval No.: 13BTY004

\section{References:}

[1] Xu Tongzhu, Liu Lunwen. Cultural Needs of Peasants in Minority Areas and Change of Government Functions [J]. Journal of Guizhou Radio \& TV University, 2008, (04).

[2] Wang Chunfu. Response Mechanism of Public Policy and Public Order [J]. Journal of Jiangxi Administration Institute, 2009, (02).

[3] Yang Xi. Chinese Minority Sports [M]. Beijing: China Pictorial Publishing House, 2004. 